\title{
Efficient Management of Delays in Project Realization: A Mixed Method Approach within a Cameroonian Banking
}

\author{
Jean Robert Kala Kamdjoug", Maxime Ngate Motcheka \\ Faculty of Social Sciences and Management, Institut Catholique of Yaounde, Catholic University of Central Africa, Cameroon
}

Copyright (C) 2015 by authors, all rights reserved. Authors agree that this article remains permanently open access under the terms of the Creative Commons Attribution License 4.0 International License

\begin{abstract}
This article focuses on key determinants of delays in the realization of an information system (IS) project. In particular, the impact of the non-adoption of project management methodology by project managers and the lack of software to manage collaboration on delays in project implementation is assessed. Using a mixed-method approach, the study found that these two determinants have a positive relationship with delays in IS project implementation. Implications for research and practice are discussed.
\end{abstract}

Keywords Project Management, Information Systems, Delay Optimization, Structural Equations, Problem Tree

\section{Introduction}

Current international economic conditions compel many companies in a competitive environment to anticipate customer needs in order to increase their satisfaction. This goal can be met through innovation that gives companies control of their growth by implementing projects that enable them to develop.

Banks work hard in order to give total satisfaction to their customers. For instance, they develop strategies and models to anticipate their needs and therefore help them in providing the best solutions. That's the reason why their project portfolio increases over the years.

In many companies around the world, the majority of projects are completed beyond the deadline. Saying "projects are late" has become familiar, providing that the perfect forecast in project management will never be. Nevertheless, there is a limit not to exceed to avoid bankruptcy. This limit can be set at $33 \%$ of the time beyond previsions. However, the off-time deliveries may have dramatic consequences on the well-being of companies. A non-exhaustive list of these consequences is: operational losses, image degradation and lack of trust in the project management team.

In 2012 , more than $50 \%$ of delays in the execution have been registered in the bank SGC (Societé Générale
Cameroun). Faced with these poor results on project achievement, this article aims to define the factors and to find ways of reducing these delays.

More specifically, the paper aims at answering the following research questions:

RQ1: What is the impact of non-adoption of project management methodology by project managers on delays in project realization?

RQ2: What is the impact of the lack of software to manage collaborative on delays in project implementation?

The rest of this paper is structured as follows: Section 2 presents the theoretical background of the study, Section 3 deals with the methodology and Section 4 with data analysis. Section 5 discusses the results of the study and Section 6 deals with implications and limits. Finally, Section 7 serves as the conclusion of the study.

\section{Theoretical Background}

\subsection{Management Project Models, Tools and Methodologies}

Unlike other management fields such as accounting and marketing, there is little literature about project management [1]. In the early twentieth century, practitioners such as Taylor and Fayol have developed approaches to solve common and recurring problems based on their experience of organization theory. Following them, practices have been institutionalized through tools and professions structuring and models were set out. The first model of project management which is design came from areas such as craft industry, civil engineering and shipbuilding. Indeed design is the stage during which the architect prepares the realization of the work or the project execution. He do simulations considering the real constraints. The architecture allows the division of work into tasks and plans its realization in time.

The entrepreneurship model comes from the model of startup development that has been adapted from "Project Management" by Middler [2]. Two aspects emerge from this 
model; the project is identified with the birth and development of a business collaboration and is largely based on trust between employees. This model highlights the advantage of creating healthy interpersonal relationships. The contractor's search for skills for the project is limited to this social network. These skills are easily found with the application of the newest models of project management in large companies through tenders or project team meetings. These practices are derived from the standard model of the Project Management Institute.

Indeed, from the 1960s, institutions have been created in order to organize project management and a standard model has emerged for project engineering. Among these institutions are: The AFITEP (Association Francophone de Management de Projects), the IPMA (International Project Management Association), and the PMI (Project Management Institute). Over the years, PMI standardizes business practices of project management and supported three major initiatives in the early 1980s (Navarre, 1993, P. 189): (i) the development of a body of knowledge in project management (the Project Management Body of Knowledge - PMBOK); (ii) the development of project certification; and (iii) the adoption of a written charter and an oath framing the profession of project management.

Project management has changed orientation despite its enrichment with various tools, formalization, standardization and dissemination of the PMI model. In fact, due to the impoverishment of developing countries, the international growth of risk and the arrival of new competitors on the engineering market, the PMI model found itself in crisis. This is due to the arrival of these new challenges and requirements [3].

Yet, manufacturing industry didn't adopt the standard model, but remained in his model set up before the formalization of the PMI model: the Taylorist model or sequential model. Project development is symbolized using a relay race [4]; its realization goes from one function to another. This model is based on three characteristics [2]: (i) integration into the company of the most needed skills for the project growth; (ii) separation of expertise in the various functions; and (iii) hierarchical coordination of professional expertise in realizing the project.

Even though this sequential organization has been effective in the past, there are now limits. Today's world requires efficiency and high speed in developing innovative products. Instead of individual and successive changes in the various functions involved in the project, a simultaneous increase of the whole project team is favored. This is the main characteristic of what is generally called concurrent engineering.

Developed in the mid-1980s, the concurrent engineering model was at first a response to the need of more rapid project development. The Japanese auto industry was the first user. Managerial principles of this model can be summarized in four points [5]:

- Phase recovery
- Heavy project supervision
- Coordination of activities

- Association with partners in development process.

This need for rapid development in project management has led to several studies on costs and delays control. The results of the first annual survey of "Observatoire des projets en France à dominante SI" launched in January 2011 by the consulting firm Daylight Group, demonstrated the main problems of IT projects in terms of time. It is reported that $70 \%$ of IT projects do not respect the initial planning and $16 \%$ end in failure. The study of Panorama Consulting Group of 1,600 worldwide organizations which have implemented an ERP project between 2005 and 2009, resulted in similar findings. $57 \%$ of projects have not respected the plan and $54 \%$ of projects exceed the initial budget ${ }^{1}$. Another study the Standish Group conducted in the United States of America revealed that only $16 \%$ of projects have been accomplished according to the forecasts ${ }^{2}$.

Faced with an increasing number of project failures due to poor preparation, lack of tools and low skills in project management methodology among others, decision makers, experts and organizations have studied the factors of success and failure of projects. Many tools and methodologies for project management have thus been developed and enriched.

Project management methodologies are developed according to a scientific approach, and sometimes on the basis of proven practices so that they can help controlling costs and time limits of a project. It is therefore reasonable to think that any methodology, suitable to the company's context, should allow decision makers to fulfill planning constraints. Therefore, delays could be due to a lack of methodology in project management. Here we state the first hypothesis:

H1: Non-appropriation of project management methodology by project managers has a positive effect on delays in project realization.

\subsection{Delays and IS Projects Success}

Several software programs have been developed to help managers in achieving project management process in better conditions. These tools propose sophisticated functions for project management - including: planning, resource management, budget management, collaboration and document sharing. Given the increasing number of projects in companies and the broad quantity of data they generate, working without software would be a great handicap for project management. Hence the second hypothesis:

H2: The lack of software to manage collaborative work is a major cause of delays in projects' implementation at the SGC.

$1 \mathrm{http}: / /$ www.sage.fr/espaces/default.aspx?tabid=5736\&articletype $=$ articlev iew\&articleid=446 $(13 / 08 / 2012)$

$2 \mathrm{http} / / /$ www.developerfusion.com/article/84858/why-projects-fail-8211-m astering-the-monster-part-1/ 


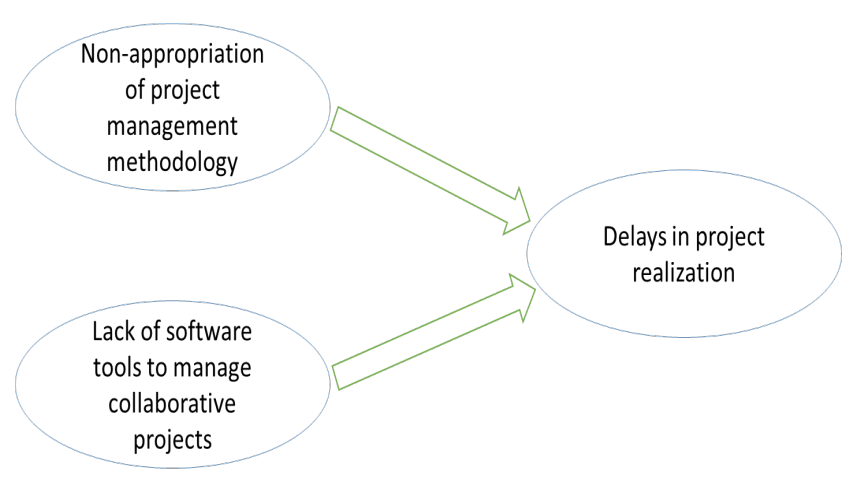

Figure 1. Study model for on time project realization

Figure 1 shows our two hypotheses of study - the links between delays in the realization of information system projects.

\section{Methodology}

This study uses a mixed method approach involving both qualitative and quantitative data. For the qualitative study, a case study was conducted within the SGC (Société Générale Cameroun), a leading Cameroonian bank which was launching a new IS. A case study strategy is suitable for studies where researchers are trying to answer the research questions such as "how" and "why" things are done [6]. In addition, case studies permit the investigation and the understanding of complex phenomena within real-life settings [7], and thus prompt theories [8]. For the quantitative phase of the study, a survey was administered to key stakeholders involved in the project.

\subsection{Research Setting}

This study took place in Société Générale Cameroun (SGC). It is a retail bank, which is a subsidiary of the French group Société Générale, with capital of 12.5 billion CFA francs (since 2010) divided between the State of Cameroon, Société Générale and 6 private investors. It was established in Cameroon in 1947 with headquarters in Douala since 1978. With a network of 26 branches, it offers services for business customers and private customers. A major actor in Cameroon's financial sector, it employs about 618 employees. In the 14th edition of the magazine Jeune Afrique's special finance publication, SGC was ranked 1st among Cameroonian banks and 134th among African banks for the 2011 period.

The Information Technology and Organization Department, which is concerned with this type of work, depends on the General Secretary. It includes the following services: local development, networks and telecommunication, help desk, data bases and systems, and organization. The latter is responsible for user access management, configuration of bank conditions, training users, updating bank procedures, and the management of banking projects. In its operation, all projects can be initiated by business users, the organization department, or the "Société Générale" group. Except for projects initiated by the group, the organization department should formalize expressions of needs, write specifications and conduct all projects from the beginning to the end.

\subsection{Data Collection}

Data collection took place between July and October 2012. There were about 40 projects underway at this time and the four major ones were:

- Automation of activities by the creation of a special ATM to centralize all operations of the autonomous port of Douala;

- Creation of a new branch at Foumban and the development of Information Technology at that site

- Creation of a virtual platform from which customers could be able to do their banking operations, and communicate more easily with the bank

- Migration to the latest version of bank ERP

The data collection was conducted in two steps qualitative and quantitative. The qualitative aspect includes: (i) non participative observation of employees during their work on IT project management; (ii) consultation of technical and non-technical documents, reports; (iii) participative observation; and (iv) semi-structured interviews. For the quantitative aspect (v) a questionnaire was administered to project managers, to prime contractors, and functional employees. This allowed us to ensure validity [9] [6].

The aim of the qualitative analysis was to understand the project management practices in that environment and be aware of the project manager's workload. The documentation helped us to understand the history of project management. This qualitative study allowed us to obtain relevant elements for the research that were used in the questionnaire design for the quantitative analysis. For the quantitative analysis, two questionnaires were developed. One questionnaire for internal customers of the project and another for the project team. The goal is to get the vision of each stakeholder involved in the project.

For customers, knowledge and experience of project management methodology were concerned. Moreover, the implications of customers in the realization of projects were assessed. 22 individuals composed of head of departments and their team members were interviewed for this group.

For the second group, the focus was the assessment of the appropriation of the company project management methodology. Here we had 8 individual researchers divided over three groups. Some were members of the INF-ORG (Information and Organisation) department that accounts for 9 project managers who are the main supervisors. Some of them were part of the 11 regular employees of the CSM (Centre of Mutual Services) who are responsible in conducting such projects. Lastly there were 5 former managers who have recently been transferred in the last six 
months to other departments. Overall, of 47 employees invited to participate to the study, 26 agreed to participate and provide useful responses for further analysis (response rate $=55 \%$ ).

\section{Data Analysis}

Analysis of data collected with questionnaires highlights the following as causes of delays: non-adoption of project management methodology, regular amendment of specifications, poor circulation of deliverables and miscommunication, poor evaluation of deadlines and unavailability of team members. Depending on the frequency of occurrence and types of causes revealed by the questionnaires, the main causes of delays identified is twofold: non-adoption of project management methodology and lack of project management software. Solutions to these two main causes had to be found in order to optimize efficiency. To ensure the effectiveness of the solutions, it is necessary to perform a causal analysis of delays. Thus, positive factor analysis was performed. This tool is a structural equation model with latent variables.

The structural equations model is a complex statistical method to relate concepts. These models are subject of extensive literature generally classified into two schools of thought. The first, which comes from [6], is built on the estimation of covariance. The second approach, from [7], is built on a least squares estimation. This work is based on Jöreskog's approach.

The aims of structural equations are twofold: an exploratory analysis and a confirmatory analysis. It is the second approach that is used here because the objective is to confirm a pre-theoretical model. It allows a hypotheses test about the relationship between observed variables and latent variables [8].

\section{Results}

The objective of the first analysis is to identify the main causes of delays in project implementation. From the causal analysis of factors explaining the delays in the project implementation, a tree of facts is proposed in Figure 2. This tree gathers the causes of problems and highlights the consequences of delays.

After this analysis, the next step was to confirm and measure the contribution of the main causes identified on delays. A measurement model and a structural model were developed in this analysis step.

\subsection{Structural Model}

A structural model is necessary to identify both the effects and determinants of causes that explain delays. Once the model is built, it must be validated by identification and analysis of parameters as suggested by [9]. Figure 3 shows the structural model and each circle is a latent variable.

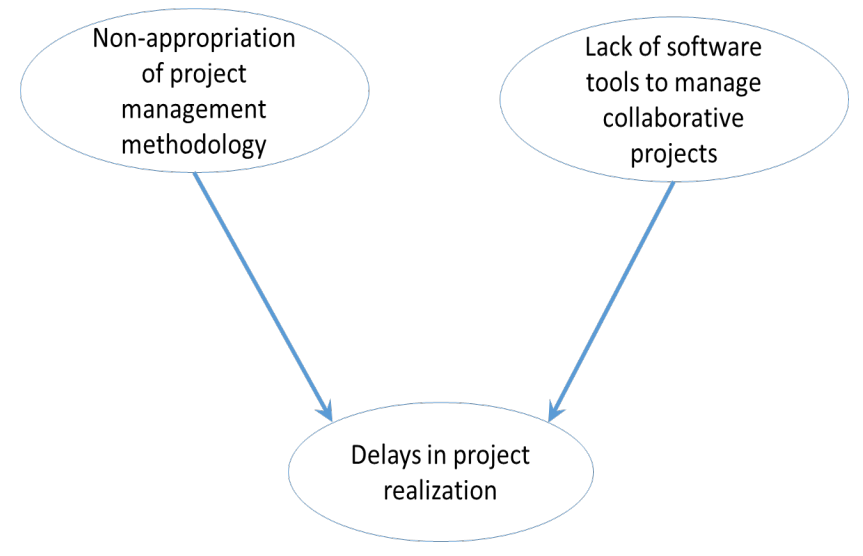

Figure 2. Study structural model.

\subsection{Measurement Model}

The measurement model involves the manifest variables that are manifestation of latent variables. Their values are provided by the completed questionnaires. Our measurement model includes 14 manifest variables shared between the latent variables as follows:

- 6 are attached to the non-adoption of the project management methodology

- 7 are attached to the absence of a project management software

- 1 is attached to penalizing delays in project management.

The complete model is presented in Appendix 1.

At the end of the data processing by LISREL software, it is important to analyze some quality model indicators to validate our model before any interpretation. As Diamantopoulos and Siguaw [10] suggest, the quality of the model must be based on a Chi-squared test and the following indices: RMSEA, standardized RMR, GFI, CFI and ECVI.

A significant Chi-squared test indicates that the model is not adequate enough to explain the data. This index assesses the importance of the difference between the observed data matrix and the matrix reproduced by LISREL applying postulated constraints in the theoretical model. A significant chi-squared test indicates that the model does not properly reproduce the information matrix. A low Chi-squared reveals a good fit. The sample size is often such that significant differences will be detected by the Chi-square test, while these differences are not "theoretically" important. It is therefore possible to maintain a model even in the presence of a significant Chi2.

The RMSEA (Root Mean Square Error of Approximation) also assesses the fit between the observed and reproduced matrix, taking into account the complexity of the model (dividing by the number of degrees of freedom). RMSEA $<0.05$ indicates a good adjustment; between 0.05 and 0.08 it is reasonable; between 0.08 and 0.10 it is poor; and lower than 0.10 it is unacceptable. 
Standardized RMR ("root-mean-square residual") is the average standardized residual. Individual residual scores greater than 2.58 in absolute value is considered important. An average value lower than 0.05 indicates an acceptable fit.

The GFI ("goodness-of-fit index") is an absolute adjustment index. It shows the proportion of variance / covariance reproduced by the model. This index must be greater than 0.90 to validate the model.

The CFI is a relative index adjustment that verifies whether a model produces a better fit than a comparison model.

ECVI "Expected Cross Validation Index" measures at which level the model could be validated with other samples of the same size drawn from the same population. It is an interesting indicator of the overall quality of a model, but there are no absolute values to gauge the index. Therefore, it is necessary to compare ECVI values obtained in different models in order to keep the model that is most likely to be replicated, that is the one that gets the smallest ECVI.

The table 1 below summarizes the values of these indices for our model.

Table 1. Indices of validity of the model, significance on threshold $\mathrm{p}<$ 0,01 .

\begin{tabular}{|c|c|c|}
\hline Indices & $\begin{array}{c}\text { Obtained } \\
\text { values }\end{array}$ & Validity thresholds \\
\hline Chi-2 & 101,26 & Neither \\
\hline RMSEA & 0,0 & Must be $<0,05$ \\
\hline Standardized RMR & 0,036 & Small as possible, preferably $<0,05$ \\
\hline GFI & 0,979 & Must be $>0,90$ \\
\hline CFI & 0,87 & Must be $>0,90$ \\
\hline ECVI & 11,250 & $\begin{array}{c}\text { The best model has the smallest } \\
\text { ECVI }\end{array}$ \\
\hline
\end{tabular}

Source: [10].

The interpretation of these indices (Table 1), allows us to conclude that our model is globally acceptable, so it fits well with our data. The relations proposed by the structural model are verified. Correlations of the structural model provided by LISREL are presented in Figure 4.

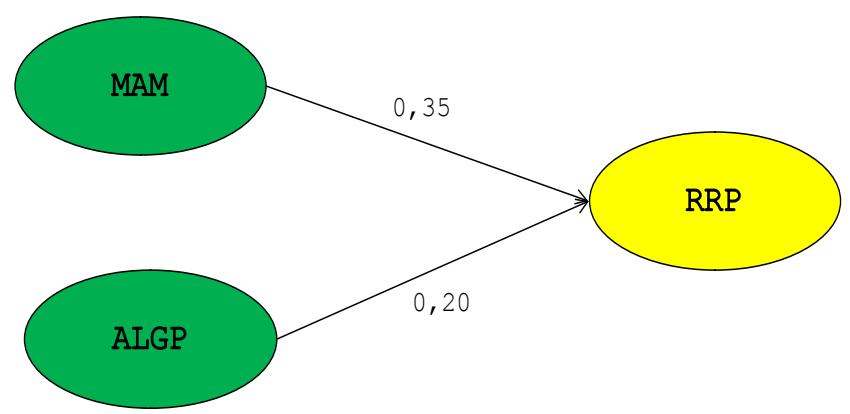

Figure 3. Hypothesis validation scheme.

Figure 3 indicates that $35 \%$ of the variance of delays in the project implementation is explained by the non-adoption of project management methodology, and $20 \%$ of that variance is explained by the absence of project management software. Therefore, the non-adoption of project management methodology and the lack of project management software explain $55 \%$ of the variance of delays in the projects, thus validating the research hypotheses.

\section{Implications and Limits}

\subsection{Implications}

Approximately $70 \%$ of projects related to the information system of the CMS are completed in time. However, in a tumultuous economic environment an enterprise which wants to maintain control of its future must manage more projects more precisely.

From the causal relationships between the various factors behind the problem identified, a problem tree has been developed. This tool helps to better perceive a problem with its causes and consequences. The development of this tree was made in three steps:

- Identification of the central problem. This will be the trunk of the tree

- Identification of its main and secondary causes (the roots of the problem)

- Identification of consequences (branches) and its side effects (branching)

The completion of these steps leads us to the problem tree of figure 4.

Most of the consequences noticed are disadvantageous to the performance of the SGC. Some of these consequences are:

- Expense increases resulting in a budget overrun and subsequent financial losses. This increase is due to the need for more human and material resources

- Financial losses. Some internal projects determine the start of a new service for which the bank signs contracts with suppliers. The contract provides a date scheduled for the first installment of a monthly payment by the bank to its supplier. The bank starts the monthly payments on the date specified in the contract, even if the benefit of the supplier is not yet effective due to delays.

- Maintain operational efficiency and productivity at a low level, because there are difficulties in effectively monitoring the operations of projects

- Delays in the achievement of objectives

- Negative perception of the headquarters by branches

- Degradation of the bank image by customers

Analysis of the data collected has allowed identification of various causes of delays. This analysis highlighted the following elements as the main causes of the problem:

- Excessive workload of project managers

- Non-adoption of project management methodology

- Lack of a scientific approach in project planning

- Absence of a management software for collaborative projects.

Given these causes, technical and organizational recommendations can be stated. For organizational, the roles 
and functions of project team members are concerned with the project workload and project culture within the company. The technical aspect relates to methods and implementation tools. The recommendations are the following:

- Strengthen projects management team to distribute the workload and improve monitoring

- Take action to insure adoption of PACTE methodology of projects by key stakeholders

- Acquire and use Microsoft Enterprise Project Management 2007, a software solution for project management. This software integrates probabilistic PERT and GANTT method's for better planning and better monitoring of projects. In addition, this software allows you to manage multiple projects and facilitates communication and collaboration.

\subsection{Study Limits}

Although the structural equation model that has been used allowed the validation of hypotheses, it is important to remember that the size of the population used is limited but it is all the population in our disposal.

Moreover, it should be noted that the planning method proposed - probabilistic PERT - has two limitations that can lead to false expectations. First, the project manager can impose an unrealistic timeframe to complete a task. Second, the estimated time to perform a task by a mathematical formula is based on assumptions and not reality.

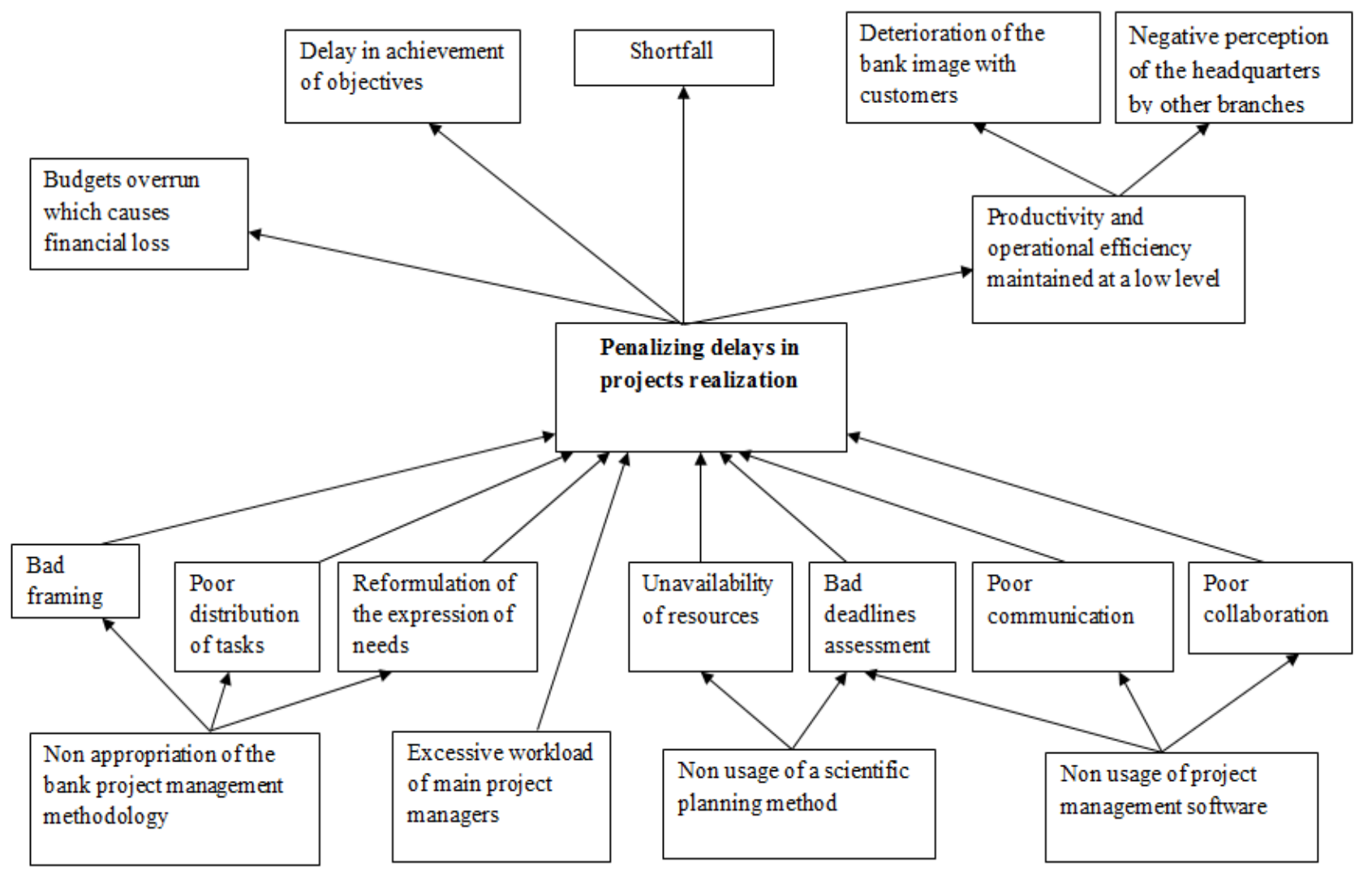

Figure 4. Problem Tree 


\section{Conclusions}

This research is unique in the Cameroonian environment. It is a new field of study in the field of project management in the banking information system. And it leads to a new approach to managing and monitoring projects within SGC. This work allows us to identify the main causes of delays in the implementation of IS projects in SGC. This situation may be common to several banks in Cameroon's financial environment. It also allows us to highli000ght the consequences of delays in project management. This can enlighten managers who are not aware. Thus, they can take action to resolve recurring problems.

\section{Appendix}

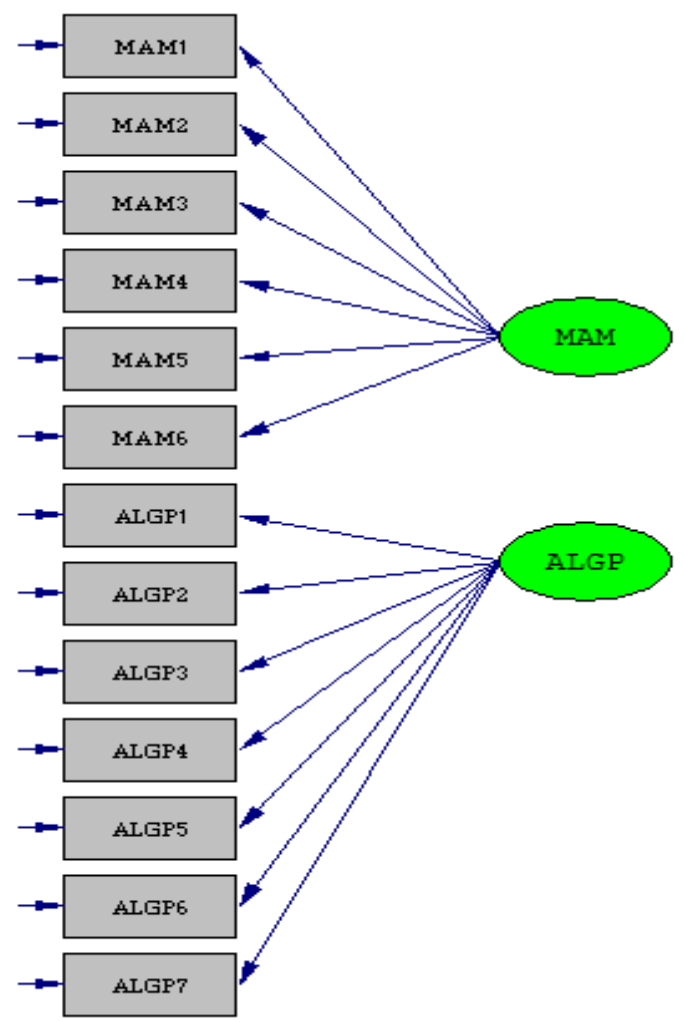

Figure 5. Model of measurement before estimation.

\section{REFERENCES}

[1] G. Garel, Pour une histoire de la question de projet,, Gérer et comprendre, 2004.

[2] C. Midler, Modèles gestionnaires et régulations économiques de la conception, Toulouse: Coopération et conception, 1996.

[3] V. Giard et C. Midler, Pilotage de projets et entreprises, Diversité et Convergences, ECOSIP., 1993

[4] H. Takeuchi et I. Nonaka, «The new product development game,» Harvard Business Review, 1986, janvier - février.

[5] G. Garel, Le management de projet, Paris: Editions La découverte, 2003.

[6] R. K. Yin, Case study research: Design and methods (2nd ed.), Newbury Park: CA: Sage Publications, 1994.

[7] K. M. Eisenhardt, «Building theories from case study research',» Academy of Management Review, vol. 14, n \% \%14, pp. 532-550, 1989.

[8] I. Benbasat, D. K. Goldstein et M. Mead, «The Case Research Strategy in Studies of Information Systems,» MIS Quarterly, vol. $11, \mathrm{n}^{\circ} \% 13$, pp. 369-386, 1987.

[9] V. Serafeimidus et S. Smithson, «Information systems evaluation as an organizational institution : experience from a case study,» Information Systems Journal, vol. 13, n% \%13, pp. 251-274, 2003

[10] K. Jöreskog et D. Sörbom, LISREL 7 - guide to the program and applications, Second edition, SPSS publications, 1989.

[11] H. Wold, Partial Least Squares, S. Kotz et N. L. Johnson, Éds., New York: Wiley, 1985, pp. 581-591.

[12] R. H. Hoyle, The structural equation modeling approach: Basic concepts and fundamental issues, R. H. Hoyle, Éd., Thousand Oaks: CA: Sage Publications, Inc., 1995, pp. 1-15.

[13] P. Roussel, F. Durreiux, E. Campoy et A. El Akremi, Méthodes d'équations structurelles : recherches et application en gestion, Paris: Economica, 2002.

[14] A. Diamantopoulos et J. A. Siguaw, Introducing LISREL, Thousand Oaks, CA : Sage., 2000.

[15] C. Navarre, «Pilotage stratégique de la firme et gestion de projets : de Ford et Taylor à Agile et IMS,» ECOSIP, pp. 181-215, 1993. 